\title{
Improvement of drug delivery with a breath actuated pressurised aerosol for patients with poor inhaler technique
}

\author{
Stephen P Newman, Alex W B Weisz, Neda Talaee, Stewart W Clarke
}

\begin{abstract}
Background The metered dose inhaler is difficult to use correctly, synchronising actuation with inhalation being the most important problem. A breath actuated pressurised inhaler, designed to help patients with poor inhaler technique, was compared with a conventional metered dose inhaler in terms of aerosol deposition and bronchodilator response.

Methods Radioaerosol deposition and bronchodilator response to $100 \mu \mathrm{g}$ salbutamol were measured in 18 asthmatic patients, who inhaled from a conventional metered dose inhaler by their own chosen metered dose inhaler technique, from a conventional metered dose inhaler by a taught metered dose inhaler technique, and from a breath actuated pressured inhaler (Autohaler).
\end{abstract}

Results In the 10 patients who could coordinate actuation and inhalation of the inhaler on their own deposition of aerosol in the lungs and bronchodilator response were equivalent on the three study days. By contrast, in the eight patients who could not coordinate the mean (SEM) percentage of the dose deposited in the lungs with their own inhaler technique $(7 \cdot 2 \%(3 \cdot 4 \%))$ was substantial lower than those attained by the taught metered dose inhaler technique $(22 \cdot 8 \%(2 \cdot 5 \%))$ and by Autohaler $(20.8 \%$ $(1 \cdot 7 \%))$.

Conclusion Although of little additional benefit to asthmatic patients with good coordination, the Autohaler is potentially a valuable aid to those with poor coordination, and should be considered in preference to a conventional metered dose inhaler in any patient whose inhaler technique is not known to be satisfactory.

Thoracic Medicine,

Royal Free Hospital

and School of

Medicine, London

NW3 2QG

$S$ P Newman

A W B Weisz

$\mathrm{N}$ Talaee

$S$ W Clarke

Reprint requests to:

Dr $S$ P Newman,

Pharmaceutical Profiles Ltd,

2 Faraday Buildings,

Highfields Science Park,

University Boulevard,

Nottingham NG7 2QP

Accepted 7 July 1991

The pressurised metered dose inhaler was introduced in $1956^{1}$ and has become the most popular inhalation device in the treatment and prophylaxis of asthma. It is compact, portable, and convenient, containing at least 200 metered doses; these features explain its widespread acceptance by patients and its continued use after several decades. It suffers from a major disadvantage, however, in that it is difficult to use correctly. ${ }^{2-5}$ It has been estimated that as many as half of adults with asthma and an even greater proportion of children derive little benefit from their metered dose inhalers because of inefficient inhaler technique. ${ }^{6}$ Further, some patients whose inhaler technique is initially satisfactory develop a poor technique with time. ${ }^{7}$

Probably the most important error confounding the use of a metered dose inhaler is failure to coordinate or synchronise the actuation of the inhaler with inhalation. ${ }^{3} \mathrm{~A}$ breath actuated pressurised inhaler (Aerolin Autohaler, 3M Riker) has been devised to help such patients. ${ }^{89}$ This device (fig 1) uses a conventional pressurised canister, which is triggered by a spring when the patient inhales through the mouthpiece at a low inhalation flow rate of $22-36 \mathrm{l} / \mathrm{min} .{ }^{8}$ We have compared aerosol deposition and bronchodilator response following inhalation from the Autohaler and from a conventional metered dose inhaler in patients with good and bad coordination.

\section{Methods}

PATIENTS

We studied 19 patients ( 10 male) with asthma aged 18-78 years (baseline forced expiratory volume in one second $\left(\mathrm{FEV}_{1}\right) 24-96 \%$ predicted). One patient was subsequently withdrawn because he failed repeatedly to keep his

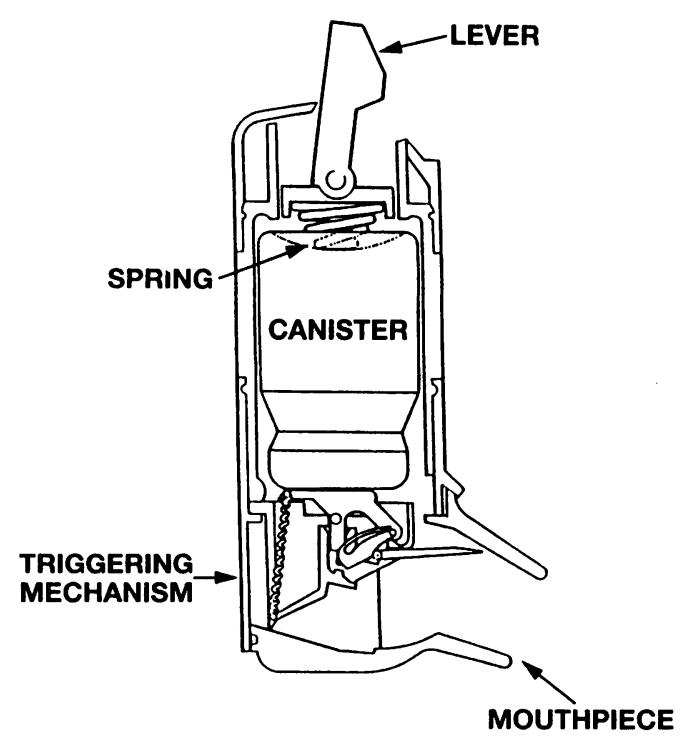

Figure 1 Breath actuated pressurised inhaler (Aerolin Autohaler, 3M Riker ). 
appointments. Immediately before the study all patients were shown to have at least $15 \%$ reversibility in $\mathrm{FEV}_{1}$ and in maximal expiratory flow at $75 \%$ forced vital capacity $\left(\dot{V} \max _{25}\right)$ after inhaling $200 \mu \mathrm{g}$ salbutamol from a pressurised metered dose inhaler. Patients withheld treatment with an inhaled beta agonist for 12 hours before each hospital visit, and inhaled ipratropium bromide was withdrawn for 24 hours and methylxanthines for $\mathbf{4 8}$ hours. Patients were issued with a short acting beta ${ }_{2}$ agonist (rimeterol) that they could use if required up to three hours before each test. Each patient gave informed consent in writing and the studies were approved both locally by the hospital's ethical practice subcommittee and by the Administration of Radioactive Substances Advisory Committee.

\section{STUDY DESIGN}

Each patient performed three radioaerosol studies on three different days separated by at least 48 hours. On the first study day (called the own metered dose inhaler day) a conventional radiolabelled metered dose inhaler was used by the patient's own chosen technique. The patient was asked to take a single metered dose using the inhalation technique that he or she normally used. No instructions on use of the inhaler were given; the mouthpiece cover was removed and the inhaler was shaken and then handed to the patient in the upright position. The second and third study days were randomised, and consisted of inhalation from a conventional metered dose inhaler by a taught technique (the taught metered dose inhaler day) and from an Autohaler. On these two days patients practised the inhalation manoeuvre with a placebo aerosol until their performance was judged to be competent. Patients were instructed to take a slow, deep inhalation, followed by 10 seconds' breath holding and exhalation via a filter. With the taught technique the metered dose inhaler was actuated by an observer during the inhalation manoeuvre. After each inhalation patients exhaled via a low resistance filter (Inspiron 002290) to trap any exhaled radioaerosol. They wore a respiratory inductance plethysmography band (Respitrace Corporation) around the chest, which enabled inhaled volume, inhaled flow rate, and breath holding time to be registered. ${ }^{10}$ We performed the study with patients' own technique before those with the taught technique or Autohaler so that their own technique would not be influenced by recent instruction.

\section{RADIOAEROSOL STUDIES}

Pressurised metered dose inhalers were labelled by the direct addition of the radionuclide technetium-99m to canisters containing salbutamol (Salbulin, 3M Riker) as described. ${ }^{11}$ Briefly, ${ }^{99 m}$ Tc is extracted in chloroform, which subsequently evaporates in an empty aerosol canister. Two millilitres of a suspension comprising propellants (chlorofluorocarbons 11, 12, and 114), surfactant (sorbitan trioleate), and salbutamol were added at below $-60^{\circ} \mathrm{C}$, and a $25 \mu \mathrm{l}$ metering valve was added by a crimper. Subsequently, each metered dose delivered about $100 \mu \mathrm{g}$ salbutamol and $20 \mathrm{MBq}{ }^{99 \mathrm{~m}} \mathrm{Tc}$. The technique was assessed by extracting metered doses via a multistage liquid impinger, ${ }^{11} 12$ which classifies aerosol into different size bands; aerosol penetrating to stages 3 and 4 of the impinger consists mainly of droplets smaller than $5 \mu \mathrm{m}$ diameter. The distributions of untreated drug, drug treated with the chloroform and ${ }^{99} \mathrm{~m}$ Tc mixture, and radiolabel on different parts of the impinger were compared. These data (table 1) showed that the distribution of radiolabel among the different parts of the impinger closely mirrored that of drug, and that the distribution of drug within the impinger was changed little by the addition of the radiolabel in chloroform. We concluded that the radiolabel would act as a marker for the presence of drug during a deposition study.

After inhalation of a single labelled dose of $100 \mu \mathrm{g}$ salbutamol a posterioanterior view of the chest and lateral view of the oropharynx were taken immediately by a gamma camera (Ohio Nuclear 110) coupled to a Nodecrest computer. Counts were corrected for attenuation during the passage of radiation to the gamma camera. Deposition on the actuator and exhaled air filter was compared with that from a metered dose collected on a further filter; activity not recovered on the actuator or on the exhaled air filter was assumed to be in the body and was fractioned according to the corrected counts from lungs and oropharynx. Activity recorded in the oesophagus and stomach was assumed to have arisen from aerosol deposited in the oropharynx. A posteroanterior ventilation scan using krypton-81m was also performed on each patient, and was used to define the lung borders on the aerosol scans; the lung fields were subsequently divided into central, intermediate, and peripheral lung zones. ${ }^{11}$

\section{LUNG FUNCTION}

$\mathrm{FEV}_{1}$ (Vitalograph Spirometer) and $\dot{V} \max _{25}$ (Ohio Spirometer plus XY plotter) were measured immediately before inhalation of the labelled dose and 15,30,60, and 90 minutes later. The highest value from three attempts was taken at each time point. Studies with the taught metered dose inhaler technique and with the Autohaler were started only if baseline $\mathrm{FEV}_{1}$ was within $15 \%$ of its value on the "own metered dose inhaler" day.

Table 1 Evaluation of radioaerosol technique: mean (SEM) percentage distribution of untreated drug, drug
treated with chloroform and technetium- $99 m$, and treated with chloroform and technetium- $99 \mathrm{~m}$, and radiolabel on the actuator, "throat," and four stages of a
multistage liquid impinger

\begin{tabular}{lrrr}
\hline & $\begin{array}{l}\text { Untreated } \\
\text { drug }\end{array}$ & \multicolumn{1}{c}{$\begin{array}{l}\text { Treated } \\
\text { drug }\end{array}$} & Radiolabel \\
\hline Actuator & $8 \cdot 6(3 \cdot 0)$ & $12 \cdot 6(2 \cdot 8)$ & $13 \cdot 9(2 \cdot 6)$ \\
Throat & $38.0(4 \cdot 5)$ & $43 \cdot 5(8 \cdot 7)$ & $41 \cdot 5(3 \cdot 7)$ \\
Stage 1 & $7 \cdot 7(1 \cdot 7)$ & $4 \cdot 0(1 \cdot 6)$ & $4 \cdot 0(2 \cdot 7)$ \\
Stage 2 & $6 \cdot 7(1 \cdot 8)$ & $4 \cdot 2(2 \cdot 0)$ & $6 \cdot 4(0 \cdot 5)$ \\
Stage 3 & $8 \cdot 6(1 \cdot 8)$ & $6 \cdot 5(4 \cdot 1)$ & $6 \cdot 5(2 \cdot 2)$ \\
Stage 4 & $30 \cdot 5(1 \cdot 6)$ & $29 \cdot 2(2 \cdot 1)$ & $27 \cdot 7(0 \cdot 8)$ \\
\hline
\end{tabular}


Figure 2 Deposition patterns of radiolabelled aerosol in a good coordinator (top) and in a bad coordinator (bottom) for studies with their own metered dose inhaler (MDI) technique, the taught MDI technique, and the Autohaler. When the bad coordinator inhaled with his own MDI technique the inhaler was actuated after completion of inhalation.
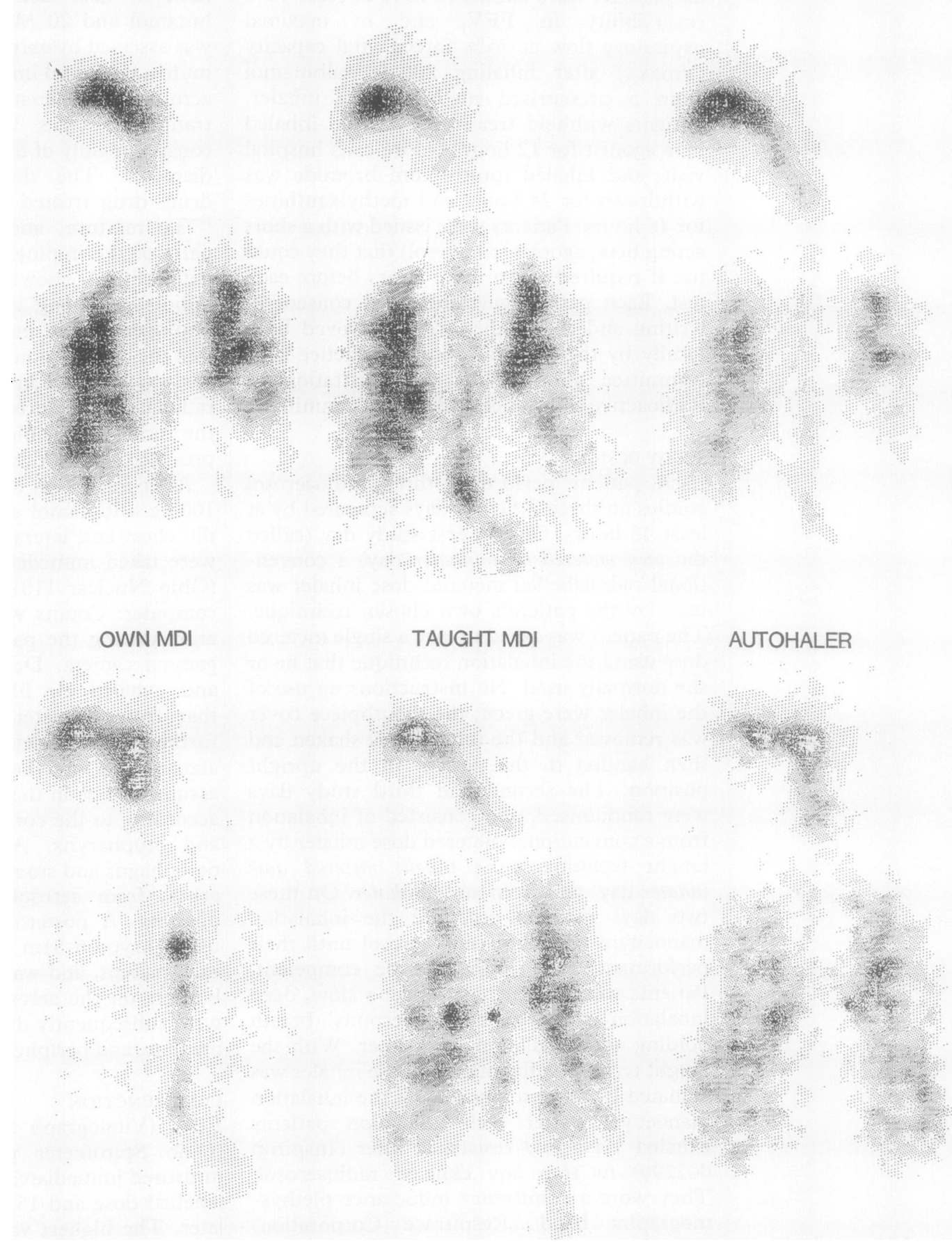

STATISTICAL ANALYSIS

Analysis of variance was used to assess the effects on deposition and bronchodilator response due to inhaler, period, and carryover from the previous inhaler. Subsequent multiple pairwise comparisons between inhalers were carried out using Bonferroni $t$ tests. ${ }^{13} \mathrm{~A}$ $\mathrm{p}$ value below 0.05 was taken to indicate statistical significance. From inspection of the inhalation manoeuvre when the patient inhaled according to his or her own technique, patients were divided into two groups, with good and bad coordination respectively; data from the two groups were tested separately.

\section{Results}

GOOD COORDINATORS

In the study using their own metered dose inhaler technique, 10 of the 18 patients (mean baseline $F E V_{1} 51 \%$ predicted, range $24-72 \%$ ) actuated the inhaler during the course of inhalation, and were hence classified as good coordinators. Most of these patients used an inhalation technique that was close to optimal; six of the 10 patients inhaled at less than $60 \mathrm{l} /$ min, and seven of the 10 patients held their breath for more than six seconds.

For the ten good coordinators there were no significant differences between the three study 
Figure 3 Mean percentage changes in FEV, (with standard errors) and in maximal expiratory flow at $75 \%$ forced vital capacity $\left(\operatorname{Vmax}_{25}\right)$ in 10 good coordinators (upper figures) and in eight bad coordinators (lower

figures), for studies with their own metered dose inhaler (MDI) technique (-), the taught $M D I$ technique $(\bullet)$, and the Autohaler (O).
\% Change from baseline $\mathrm{FEV}_{1}$ : good coordinators

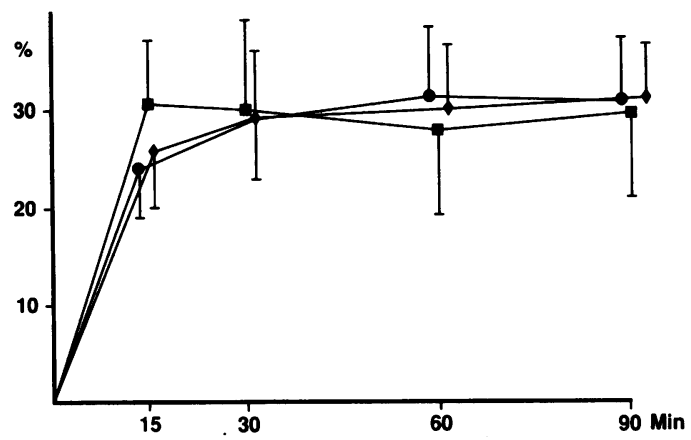

$\%$ Change from baseline $\mathrm{FEV}_{1}$ : bad coordinators

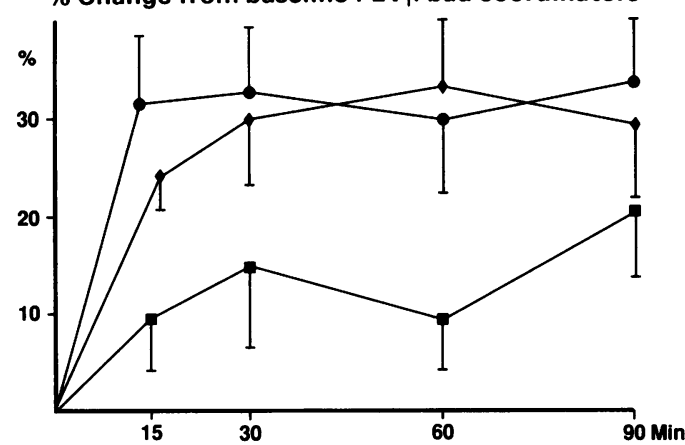

days in the deposition fractions in lungs, oropharyx, actuator, and exhaled air (table 2). Typical deposition patterns are shown in figure 2. There was a trend towards less deposition in the lungs for inhalation by the taught metered dose inhaler technique, but this did not reach statistical significance. Regional deposition within the lungs was also similar for the three study days: the mean (SE) percentage of the dose in the peripheral lung zone was $6.5(1.0)$ for "own metered dose inhaler," $5.4(1.0)$ for "taught metered dose inhaler," and 7.1 (1.2) for the Autohaler.

Baseline values of $\mathrm{FEV}_{1}$ (own metered dose inhaler $1.92(0.29) 1$, taught metered dose inhaler $1.87(0.29) 1$, Autohaler $1.97(0.30) 1)$ and $\dot{V} \max _{25}$ were similar on the three study days. Areas under the $\mathrm{FEV}_{1}$ and $\mathrm{V}_{\max } 25$ bronchodilator response curves did not vary significantly between the three studies (fig 3 ).

BAD COORDINATORS

Eight patients (mean baseline $\mathrm{FEV}_{1} 57 \%$ predicted, range $31-96 \%$ ) were observed to have bad coordination with their own metered dose inhaler technique; of these, four actuated the inhaler before the beginning of inhalation and four actuated it after the completion of inhalation.

The fractionation of deposition for these eight patients is shown in table 2; compared with the other two studies, there was a significant reduction in deposition in the lungs $(\mathrm{p}<0.01)$ during inhalation by their own metered dose inhaler technique. The percentage of the dose deposited in the lungs with their own metered dose inhaler technique was less than $1 \%, 11 \cdot 8 \%, 8 \cdot 6 \%$, and $28.3 \%$ in the four patients who actuated the metered dose inhaler before inhalation; these patients had delay times before starting to inhale of about 3 , $1.5,1.0$, and 0.5 seconds, suggesting an inverse
\% Change from baseline $\dot{V}_{\max _{25}}$ : good coordinators

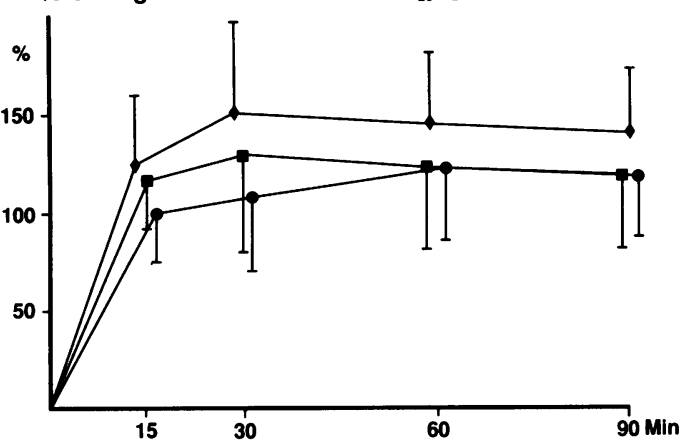

\% Change from baseline $\dot{V} \max _{25}$ : bad coordinators

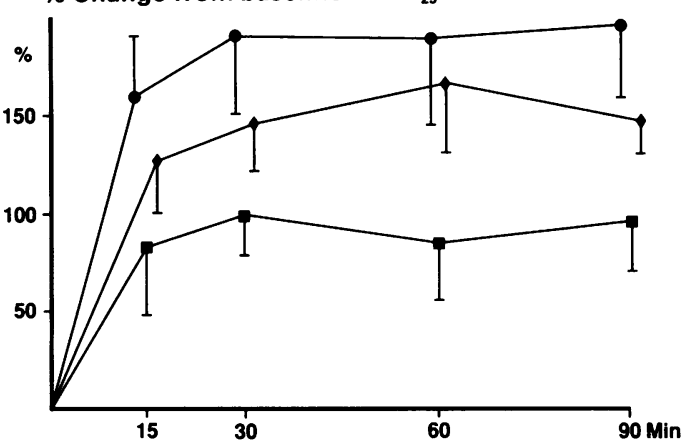

relation between lung deposition and delay time. In three of the four patients who actuated the metered dose inhaler after inhaling, less than $2 \%$ of the dose reached the lungs (fig 2); in the fourth patient lung deposition was $5 \%$ of the dose, but this was confined to a single area in the large bronchi of one lung. Deposition in the peripheral lung zone was $8.6 \%(0.9 \%)$ of the dose for "taught metered dose inhaler" and $8.4 \%(1 \cdot 1 \%)$ for the Autohaler, but we did not attempt to quantify this measure for "own metered dose inhaler" as it was immeasurably small in five of the eight patients.

There was little variation in either baseline $\mathrm{FEV}_{1}$ (own metered dose inhaler $1.36(0.15) 1$, taught metered dose inhaler $1.39(0.16) 1$, Autohaler $1.41(0.15) 1)$ or baseline $\operatorname{Vmax}_{25}$ on the three study days. The area under the FEV bronchodilator response curve was significantly $(p<0.05)$ greater with taught metered dose inhaler and Autohaler than with "own metered dose inhaler" (fig 3). The area under the V́max bronchodilator response curve was significantly $(p<0.05)$ greater for the Autohaler than for "own metered dose inhaler."

Table 2 Mean (SEM) percentage of the aerosol dose located at various sites after inhalation by good coordinators $(n=10)$ and by bad coordinators $(n=8)$

\begin{tabular}{|c|c|c|c|}
\hline Site & Own MDI & Taught $M D I$ & Autohaler \\
\hline \multicolumn{4}{|c|}{ GOOD COORDINATORS } \\
\hline Lungs & $18 \cdot 6(2.9)$ & $12 \cdot 8(1 \cdot 8)$ & $17 \cdot 5(2 \cdot 8)$ \\
\hline Oropharynx & $64 \cdot 4(3 \cdot 8)$ & $71 \cdot 1(2 \cdot 5)$ & $61 \cdot 2(4 \cdot 5)$ \\
\hline Actuator & $16 \cdot 1$ & $15 \cdot 8(1 \cdot 2)$ & $21 \cdot 0(2 \cdot 8)$ \\
\hline Exhaled & 0.7 & $0.3(0 \cdot 1)$ & $0.3(0.1)$ \\
\hline \multicolumn{4}{|c|}{ BAD COORDINATORS } \\
\hline Lungs & $7 \cdot 2(3 \cdot 4)$ & $22 \cdot 8(2 \cdot 5)^{\star}$ & $20 \cdot 8(1 \cdot 7)^{\star}$ \\
\hline Oropharyr & $67 \cdot 7(4 \cdot 7)$ & $59 \cdot 3(2 \cdot 3)$ & $60 \cdot 7(2 \cdot 2)$ \\
\hline Actuator & $23.5(3.8)$ & $17.6(0.9)$ & $18 \cdot 2(1 \cdot 3)$ \\
\hline Exhaled & $1.7(0.9)$ & $0.3(0 \cdot 1)$ & $0.2(0 \cdot 1)$ \\
\hline
\end{tabular}

${ }^{\star} \mathrm{p}<0.01$ in the comparison with own metered dose inhaler (MDI) technique. 


\section{Discussion}

A breath actuated pressurised aerosol was first described almost 20 years ago, ${ }^{14}$ but the early model was relatively unsuccessful for several reasons. The inhaler was rather bulky, its operation was somewhat noisy and violent, and some patients had difficulty in generating a sufficient flow rate to trigger the mechanism. Additionally, the original breath actuated inhaler contained the non-selective beta agonist isoprenaline. The new breath actuated inhaler (Aerolin Autohaler) is compact and quiet in operation, functions at a low inhaled flow rate that is easily achieved by patients with obstructive airways disease ${ }^{15}$ and is optimal for drug delivery, ${ }^{16-18}$ and contains the selective beta ${ }_{2}$ receptor agonist salbutamol.

Although not necessarily reflecting the population at large, the asthmatic patients entering our study fell into two approximately equal groups with good and bad coordination when using a metered dose inhaler according to their own chosen technique. In the 10 good coordinators the Autohaler gave no additional benefit over a conventional metered dose inhaler. Surprisingly, however, there was a trend towards less lung deposition with the taught technique, which resulted primarily from data from two individuals. Overall, this difference was not significant, but we cannot exclude the possibility that while instructing patients in the "correct" technique we were introducing some additional and undetected error that caused this technique to be inferior to their own chosen method. The use of a metered dose inhaler with the mouth held open results in greater deposition than when the mouth is closed, ${ }^{19}$ but this cannot explain the observed result because every patient used a metered dose inhaler with the lips firmly closed round the mouthpiece.

The data were substantially different in the bad coordinators. In four patients who chose to actuate the metered dose inhaler after inhaling both lung deposition and bronchodilator response were substantially reduced, and we failed to observe a characteristic deposition pattern of aerosol in the lungs on the gamma camera scans. This arose because there was no inhaled airstream available to conduct aerosol deep into the lungs. The observation of a greatly reduced bronchodilator response when the dyscoordination occurs at the end of inhalation is in agreement with the results of earlier studies. ${ }^{1620}$ The data from the four patients who delayed between actuating the metered dose inhaler and starting to inhale suggests that drug delivery and delay time are inversely related, and that a minimal delay of less than one second may not compromise drug delivery; this again is in agreement with the findings of earlier studies. ${ }^{1620}$

In our patients the Autohaler thus "corrected" for poor coordination, both drug deposition and the bronchodilator response being equivalent to those obtained with a correctly used conventional metered dose inhaler. Subjectively, we were impressed by the ease with which several patients with a very poor metered dose inhaler technique learnt to use the Autohaler successfully. It would be interesting to know how effectively such patients retain their ability to use the Autohaler, but this was outside the scope of the present study. Evidence from a clinical study ${ }^{21}$ suggests that patients prefer the Autohaler to a conventional metered dose inhaler and that they find the former easier to use. The Autohaler will not, however, help patients who stop inhaling at the moment of actuation, ${ }^{22}$ and the device must be formulated with "ozone friendly" propellants ${ }^{23}$ in the near future. The Autohaler should, however, be a valuable alternative to dry powder inhalers ${ }^{1224}$ and spacer devices ${ }^{25}$ for patients unable to use a conventional pressurised metered dose inhaler because of coordination difficulties.

We wish to thank $3 \mathrm{M}$ Health Care for their financial support of this study and Mr J Tunnicliffe of Sheffield Statistical Services this study and Mr J Tunnicliffe of She

1 Freedman T. Medihaler therapy for bronchial asthma: a new type of aerosol therapy. Postgrad Med 1956;20:667-73.

2 Epstein SW, Manning CPR, Ashley MJ, Corey PN. Survey of the clinical use of pressurised aerosol inhalers. Can Med Ass $J$ 1979;120:813-6.

3 Crompton GK. Problems patients have using pressurised aerosol inhalers. Eur J Respir Dis 1982;63(suppl 119): 57-65.

4 Pedersen S, Frost L, Arnfred T. Errors in inhalation technique and efficiency in inhaler use in asthmatic children. Allergy 1986;41:118-24.

5 Lindgren S, Bake B, Larsson S. Clinical consequences of inadequate inhalation technique in asthma therapy. Eur $J$ Respir Dis 1987;70:93-8.

6 Crompton GK. Adult patients' difficulties with inhalers. In: Inspiration: developments in inhalation therapy. Oxford: Medicine Publishing Foundation, 1989:1-6. (Symposium series No 26.)

7 Paterson IC, Crompton GK. Use of pressurised aerosols by asthmatic patients. $B M J 1976 ; \mathrm{i}: 76-7$.

8 Baum EA, Bryant AM. The development and laboratory testing of a novel breath-actuated pressurised inhaler. $J$ Aerosol Med 1988;1:219-20.

9 Baum EA. Design, development and testing of a new breath actuated inhaler. In: Inspiration: developments in inhalation therapy. Oxford: Medicine Publishing Foundation 1989:21-30.

10 Stradling JR, Chadwick GA, Quirk C, Phillips T Respiratory inductance plethysmography: calibration techniques, their validation and effects of posture. Bull Eur Physiopathol Respir 1985;21:317-24.

11 Newman SP, Clark AR, Talaee N, Clarke SW. Pressurised aerosol deposition in the human lung with and without an “open" spacer. Thorax 1989;44:706-10.

12 Newman SP, Morén F, Trofast E, Talaee N, Clarke SW. Deposition and clinical efficacy of terbutaline sulphate from Turbuhaler, a new multi-dose powder inhaler. Eur Respir J 1989;2:247-52.

13 Glantz SA. Primer of biostatistics. New York: McGraw Hill, 1987:276-7.

14 Crompton GK. Breath-activated aerosol. BMJ 1971;ii: 652-3.

15 Wallace WAH, Lenny J, Cooksey E, Greening AP, Crompton GK. Ability of patients with severe airflow limitation to trigger a new breath-actuated inhaler. Thorax 1989; to trigger

16 Newman SP, Ravia D, Clarke SW. How should a pressurised beta-adrenergic bronchodilator be inhaled? Eur J Respir Dis 1981;62:3-20.

17 Newman SP, Pavia D, Garland N, Clarke SW. Effects of various inhalation modes on the deposition of radioactive pressurised aerosols. Eur J Respir Dis 1982;63(suppl 119):57-65.

18 Lawford P, McKenzie D. Pressurised aerosol inhaler technique: how important are inhalation from residual volume, inspiratory flow rate and time interval between puffs? Br J Dis Chest 1983;77:276-81.

19 Dolovich MB, Ruffin RE, Roberts R, Newhouse MT. Optimal delivery of aerosols from metered dose inhalers. Chest 1981;80(suppl):911-5.

20 Rivlin J, Mindorff C, Levison H, Kazim F, Reilly P, Worsley $G$. Effect of administration technique on bronchodilator response to fenoterol in a metered dose inhaler. Pediatrics 1983;102:470-2.

21 Crompton GK, Duncan J. Clinical assessment of a new breath-actuated inhaler. Practitioner 1989;233:268-9.

22 Pedersen S, Mortensen S. Use of different inhalation devices in children. Lung 1990;168(suppl):653-7.

23 Newman SP. Metered dose pressurised aerosols and the ozone layer. Eur Respir J 1990;3:495-7.

24 Crompton GK. Clinical use of dry powder systems. Eur $J$ Respir Dis 1982;63(suppl 122):96-8.

25 König P. Spacer devices used with metered dose inhalers. Breakthrough or gimmick? Chest 1985;88:276-84.

26 Dolovich MB, Ruffin RE, Corr D, Newhouse MT. Clinical evaluation of a simple demand-inhalation MDI aerosol delivery device. Chest 1983;84:36-41. 